\title{
Methyl jasmonate induced overproduction of eleutherosides in somatic embryos of Eleutherococcus senticosus cultured in bioreactors
}

\author{
Abdullah Mohammad Shohael \\ Research Center for the Development of Advanced Horticultural Technology \\ Chungbuk National University \\ Cheongju 361-763, South Korea \\ Tel: 82432613245 \\ Fax: 82432725369 \\ E-mail: sohaelam@yahoo.com \\ Hosakatte Niranjana Murthy \\ Department of Botany \\ Karnatak University \\ Dharwad - 580 003, India \\ Tel: 918362215314 \\ Fax: 918362747884 \\ E-mail: nmurthy60@hotmail.com

\section{Eun-Joo Hahn} \\ Research Center for the Development of Advanced Horticultural Technology \\ Chungbuk National University \\ Cheongju 361-763, South Korea \\ Tel: 82432613245 \\ Fax: 82432725369 \\ E-mail: ejhahn@chungbuk.ac.kr \\ Kee-Yoeup Paek* \\ Research Center for the Development of Advanced Horticultural Technology \\ Chungbuk National University \\ Cheongju 361-763, South Korea \\ Tel: 82432613245 \\ Fax: 82432725369 \\ E-mail: paeeky@chugbuk.ac.kr
}

Financial support: This work is financially supported by the Ministry of Education and Human Resources Development (MOE), the Ministry of Commerce, Industry and Energy (MOCIE) and the Ministry of Labor (MOLAB), South Korea.

Keywords: eleutherosides, elicitation, methyl jasmonate, secondary metabolite, siberian ginseng, suspension culture.

Abbreviations: 2,4-D: 2,4-dichlorophenoxy acetic acid

HPLC: high performance liquid chromatography

MJ: methyl jasmonate

MS: Murashige and Skoog

This study was concentrated on the production of eleutherosides and chlorogenic acid in embryogenic suspension cultures of Eleutherococcus senticosus by exposing them to different concentrations $(50-400 \mu \mathrm{M})$ of methyl jasmonate (MJ) during the culture period. In the bioreactor cultures, eleutheroside content increased significantly by elicitation of MJ, however, the fresh weight, dry weight and growth ratio of embryos was strongly inhibited by increasing $\mathrm{MJ}$ concentrations. The highest total eleutheroside (7.3 fold increment) and chlorogenic acid (3.9 fold increment) yield was obtained with $200 \mu \mathrm{M}$ MJ treatment. There was $1.4,3.4$ and 14.9 fold increase in the eleutheroside $B, E$, and E1 production respectively with such elicitation treatment.
These results suggest that $\mathrm{MJ}$ elicitation is beneficial for eleutheroside accumulation in the embryogenic cell suspension cultures.

Eleutherococcus senticosus Rupr. \& Maxim is popularly known as Siberian ginseng or Eleuthero is an important medicinal plant belonging to the same Araliaceae family as ginseng (Panax spp.) and was naturally distributed in northeastern Asia and now extensively used in USA (Yat et al. 1998). Roots and rhizome of the plant have long been used as a stimulant and enhance overall resistance to diseases and stress (Farnsworth et al. 1985). Extracts from the plant showed analgesic, anti-inflammatory, antipyretic

*Corresponding author 
and diuretic action. Active components of Eleutherococcus species include (1) phenylpropane compounds: synergine = eleuthroside $\mathrm{B}$, sinaptic alcohol, chorogenic acid, caffeic acid derivatives; (2) lignans: syringaresinol-4,4"-O-B-Ddiglycoside E (D); syringaresinol-4-O-B-D-glycoside, syringaresinol; (3) coumarins: isofraxidine 7-O glucoside and its aglycone-isoraxidine; (4) polysaccharides; and (5) other compounds, such as oleanic acid, aromatic oils, sugar. These active components showed positive effects on cellular defense and physical fitness in man (Szolomicki et al. 2000). E. senticosus is listed as threatened species because of excessive commercial harvest from natural habitat. Propagation of the plants by seed is difficult because over eighteen months stratification is required for germination of zygotic embryos. So, the plant tissue culture process has been looked at as a potential alternative for the more efficient mass propagation method. Recently, induction of somatic embryogenesis has been reported (Choi et al. 1999). Somatic embryos were successfully cultivated in bioreactors and germinated somatic embryos are used as raw material for medicinal purposes, but the accumulation of physiologically active eleutherosides in germinating embryos was low.

Elicitation has been proved to be effective way to increase secondary metabolite production. A number of elicitors and precursors such as methyl jasmonate (MJ) have been used successfully for enhancing production of secondary metabolites such as saikosaponins, taxoids, plaxitaxel and baccatins, ginsenosides during cell cultures of many plant species (Yukimune et al. 1996; Ketchum et al. 1999; Yu et al. 2000; Aoyagi et al. 2001; Yu et al. 2002; Kim et al. 2004; Thanh et al. 2005). In recent years, we have been searching for a strategy that could significantly affect the accumulation of eleutherosides by focusing on commercially valuable eleutherosides as a research target. In the present study, MJ was employed in embryogenic suspension of E. senticosus in order to examine the impacts on eleutherosides production.

\section{MATERIALS AND METHODS}

Induction of somatic embryogenesis and maintenance of stock cultures of embryos

Young leaves (2 $\mathrm{cm}$ in length) of E. senticosus were collected from in vitro grown plants and cut into $5 \times 5 \mathrm{~mm}$ pieces, cultured on Murashige and Skoog medium (MS, Murashige and Skoog, 1962; pH 5.8; Duchefa, Haarlem, Netherlands) with $1 \mathrm{mg} \mathrm{L}^{-1}$ 2,4-dichlorophenoxy acetic acid $(2,4-\mathrm{D}), 3 \%(\mathrm{w} / \mathrm{v})$ sucrose and $0.2 \%(\mathrm{w} / \mathrm{v})$ gel rite and cultures were maintained in dark at $25^{\circ} \mathrm{C}$. Embryogenic callus was developed from the leaves within twelve weeks after culture. Embryogenic callus was maintained on MS liquid medium supplemented with $1 \mathrm{mg} \mathrm{L}^{-1}$ 2,4-D, 3\% $(\mathrm{w} / \mathrm{v})$ sucrose and $0.2 \%(\mathrm{w} / \mathrm{v})$ gel rite by sub-culturing once in four weeks.

\section{Embryogenic cell suspension culture}

Embryogenic cells of E. senticosus were transferred to MS liquid medium supplemented with $1 \mathrm{mg} \mathrm{L}^{-1} 2,4-\mathrm{D}$ and suspension cultures were sub-cultured at every two weeks interval. To induce somatic embryos, 2 weeks old embryogenic cell clumps were filtered through a sterile 212 $\mu \mathrm{m}$ stainless steel sieve to remove the larger clumps. The suspension was allowed to settle for $5 \mathrm{~min}$ for easier removal of the used medium. About $500 \mathrm{mg}$ of cell clumps was transferred to $100 \mathrm{~mL}$ MS liquid medium without 2,4$\mathrm{D}$ in $300 \mathrm{~mL}$ Erlenmeyer flasks. The cultures were incubated at $100 \mathrm{rpm}$ on a gyratory shaker (SI-600R, Jeio Tech, Seoul, South Korea) in dark at $25^{\circ} \mathrm{C}$. At the end of four weeks of culture, the content of flask was passed through different stainless steel sieves to separate different stages of embryos $(>800 \mu \mathrm{m}=$ cotyledonary; $600 \mu \mathrm{m}=$ torpedo; $420 \mu \mathrm{m}=$ heart; $<420 \mu \mathrm{m}$ globular). Cotyledonary embryos were used as explants for establishing subsequent cultures.

Table 1. The effect of MJ on Eleutherococcus senticosus embryogenic suspension after six weeks of bioreactor culture.

\begin{tabular}{|c|c|c|c|}
\hline \multirow{3}{*}{$\begin{array}{l}\text { MJ concentration } \\
(\mu \mathrm{M})\end{array}$} & \multicolumn{2}{|c|}{ Biomass } & \multirow{3}{*}{ Growth ratio ${ }^{z}$} \\
\hline & Fresh weight (FW) & Dry weight (DW) & \\
\hline & $\left(g^{-1}\right)$ & $\left(g^{-1}\right)$ & \\
\hline 0 & $102.65 a^{y}$ & $11.32 a$ & 20.36 \\
\hline 50 & 103.16a & $10.60 a$ & 19.01 \\
\hline 100 & $104.66 a$ & $10.10 b$ & 18.05 \\
\hline 150 & $102.52 a$ & $9.52 c$ & 16.96 \\
\hline 200 & $99.25 b$ & $9.29 c$ & 16.52 \\
\hline 300 & $88.81 \mathrm{c}$ & $7.58 \mathrm{~d}$ & 13.30 \\
\hline 400 & $18.30 d$ & $2.91 \mathrm{e}$ & 4.49 \\
\hline
\end{tabular}




\section{Establishment of large scale suspension cultures in bioreactors}

Ten grams of cotyledonary somatic embryos were transferred to $3 \mathrm{~L}$ balloon type bubble bioreactor with $2 \mathrm{~L}$ MS liquid medium with $3 \%(\mathrm{w} / \mathrm{v})$ sucrose and $4 \mathrm{mg} \mathrm{L} \mathrm{L}^{-1}$ $\mathrm{GA}_{3}$. The $\mathrm{pH}$ of the medium was adjusted to 5.8 before autoclaving by using $0.1 \mathrm{~N}$ hydrochloric acid or $0.1 \mathrm{~N}$ sodium hydroxide. The volume of input air was adjusted to $0.1 \mathrm{v} / \mathrm{v}$ (air volume/culture volume) per min. Cultures were kept under a $16 \mathrm{hrs}$ photoperiod at $35 \mu \mathrm{mol} \mathrm{m} \mathrm{m}^{-2} \mathrm{~s}^{-1}$ photosynthetic photon flux. In an elicitation experiment different concentrations of $\mathrm{MJ}(0,50,100,150,200,300$ or $400 \mu \mathrm{M})$ was added to the cultures on the day of inoculation. The fresh and dry weights were recorded after 6 weeks of culture. Dry weight was determined after drying the biomass for $24 \mathrm{hrs}$ at $60^{\circ} \mathrm{C}$. Data were subjected to Duncan's multiple range tests using SAS program (Version 6.12, SAS Institute Inc., Cary, USA).

\section{Determination of eleutherosides}

Germinated somatic embryos were dried and powdered (2 g) with a blender and extracted with $60 \%$ aqueous methanol $(2 \times 50 \mathrm{~mL})$ for $30 \mathrm{~min}$. each at $60^{\circ} \mathrm{C}$, and filtered through filter paper (No. 2, $90 \mathrm{~mm}$, Advantec, Toyo, Japan). The combined extract, was evaporated to dryness in vacuum and washed with $50 \mathrm{ml}$ of ether. The insoluble fraction was dissolved in water and extracted with $n$-butanol (water saturated). The organic phase was evaporated to dryness, dissolved in $(10 \mathrm{~mL})$ high performance liquid chromatography (HPLC) grade methanol and filtered through $0.45 \mu \mathrm{m}$ membrane filter (Polyvinylidene difluoride, Whatman, USA) filter. Eleutherosides were quantified by HPLC (Waters 2690 separation modules, Waters, USA) equipped with a Symmetry ${ }^{\circledR}$ C 18 column (4.6 $\mathrm{mm} \times 250 \mathrm{~mm}$, Waters, USA) by following the procedure described previously (Apers et al. 2005). Eleutherosides and chlorogenic acid were separated using a flow rate $0.8 \mathrm{~mL} \mathrm{~min}^{-1}$ with water (solvent $\mathrm{A}$ ) and acetonitrile (solvent B) as the mobile phase. The elution programme was: initially $90: 10$ (A:B) with isocratic elution for $5 \mathrm{~min}$ followed by linear gradient to $80: 20$ in $22 \mathrm{~min}$, linear gradient to $60: 40$ in $15 \mathrm{~min}$, isocratic for $5 \mathrm{~min}$, linear gradient to the starting conditions (90:10) in $5 \mathrm{~min}$ and isocratic for $5 \mathrm{~min}$ (equilibration time). Quantification was based on ultraviolet absorption at $216 \mathrm{~nm}$. The peak areas corresponding to eleutherosides from the samples, with same retention time as authentic eleutherosides and chlorogenic acid. Retention times were 9.86, 13.10, 21.90 and $31.20 \mathrm{~min}$ for eleutheroside B, chlorogenic acid, eleutheroside $\mathrm{E}$ and $\mathrm{E} 1$ respectively.

\section{RESULTS AND DISCUSSION}

The growth and secondary metabolite accumulation by the embryos of E. senticosus, cultivated in bioreactor cultures are presented in Table 1 and Table 2 . The embryos in the untreated cultures reached $102.65 \mathrm{~g} \mathrm{~L}^{-1}$ fresh weight and $11.32 \mathrm{~g} \mathrm{~L} \mathrm{~L}^{-1}$ dry weight. Growth of embryos was significantly affected by the application of MJ. There was slight increment in fresh weight of embryos $\left(104.66 \mathrm{~g} \mathrm{~L}^{-1}\right)$ when compared to the control (Table 1). However, the fresh weight, dry weight and growth ratio were decreased with increasing MJ concentration. On the other hand, eleutheroside content was significantly enhanced by the addition of MJ. Amount of total eleutherosides and chlorogenic acid increased with increasing $\mathrm{MJ}$ concentration, and reached a maximum at $200 \mu \mathrm{M} \mathrm{MJ}$ representing 7.3 fold $\left(649.95 \mu \mathrm{g} \mathrm{g}^{-1} \mathrm{DW}\right)$ and 3.9 fold $(4.48$ $\left.\mathrm{mg} \mathrm{g}^{-1} \mathrm{DW}\right)$ increases over controls respectively. There were 1.4, 3.4 and 14.9 fold increments in eleutheroside B, E and E1 respectively compared to the control.

The accumulation of secondary metabolites in plants is part of the defense response against pathogenic attack, which is triggered and activated by elicitors, the signal compounds of plant defense responses (Zhao et al. 2005). Therefore, the treatment of plant cells with biotic and/or abiotic elicitors has been a useful strategy to enhance secondary metabolite production in cell cultures. The most frequently used elicitors in previous studies were fungal

Table 2. The effect of MJ on accumulation of eleutherosides and chlorogenic acid in somatic embryos of Eleutherococcus senticusus cultured in bioreactors ${ }^{z}$.

\begin{tabular}{|c|c|c|c|c|c|}
\hline \multirow{2}{*}{$\begin{array}{c}\text { MJ concentration } \\
(\mu \mathrm{M})\end{array}$} & \multicolumn{4}{|c|}{ Eleutherosides ( $\left.\mu \mathrm{g} \mathrm{g}^{-1} \mathrm{DW}\right)$} & \multirow{2}{*}{$\begin{array}{c}\text { Chlorogenic acid } \\
\text { (mg g } \mathrm{mW}^{-1} \mathrm{DW}\end{array}$} \\
\hline & B & $\mathbf{E}$ & E1 & Total & \\
\hline 0 & $25.55 c^{y}$ & $28.60 \mathrm{e}$ & $34.55 f$ & $88.70 f$ & $1.14 \mathrm{e}$ \\
\hline 50 & $26.73 c$ & $89.05 c$ & $119.96 e$ & $235.74 \mathrm{e}$ & $2.01 d$ \\
\hline 100 & $27.95 c$ & $93.95 b$ & $150.00 d$ & $271.90 d$ & $2.38 c$ \\
\hline 150 & $32.70 \mathrm{~b}$ & $89.00 c$ & $315.50 b$ & $437.20 b$ & $4.04 b$ \\
\hline 200 & $37.40 \mathrm{a}$ & $99.40 a$ & $517.50 a$ & $649.95 a$ & $4.48 a$ \\
\hline 300 & $33.05 b$ & $90.90 \mathrm{c}$ & $238.15 c$ & $366.45 c$ & $2.43 c$ \\
\hline 400 & $31.51 \mathrm{~b}$ & $85.26 d$ & $159.56 \mathrm{~d}$ & $276.33 d$ & $1.33 \mathrm{e}$ \\
\hline
\end{tabular}

${ }^{\mathrm{y}}$ Mean separation within column by Duncan's multiple range test at $p<0.05$.

${ }^{\mathrm{z}}$ Data was taken after 6 weeks of culture. 
carbohydrates, yeast extract, $\mathrm{MJ}$ and chitosan. MJ, a proven signal compound, is the most effective elicitor of taxol production in Taxus chinensis Roxb. (Wu and Lin, 2003) and ginsenoside production in Panax ginseng C.A. Meyer(Yu et al. 2000; Yu et al. 2002; Kim et al. 2004; Thanh et al. 2005) cell/organ culture. In the present study, the effect of different concentrations of MJ on embryogenic cell growth and eleutheroside accumulation was tested and results reveled that addition of $200 \mu \mathrm{M}$ MJ was suitable for optimum accumulation of eleutheroside B, E, E1 and chlorogenic acid. However, addition of $\mathrm{MJ}$ at higher concentration (above $100 \mu \mathrm{M}$ ) was detrimental for biomass accumulation. Similar to the present results, MJ inhibited the cell growth and promoted the secondary metabolite production with cell/adventitious root cultures of Bupleurum falcatum L. (Aoyagi et al. 2001), Taxus spp. (Yukimune et al. 1996; Ketchum et al. 1999) and Panax ginseng C.A. Meyer (Kim et al. 2004; Thanh et al. 2005). Differential accumulation of eleutherosides was observed during elicitation experiments (Table 2). Eleutheroside E1 content was highest among the different eleutherosides produced by the suspended somatic embryos. Similar to the present observation differential accumulation of secondary compounds have been reported during cell/organ cultures of Panax ginseng (Kim et al. 2004; Thanh et al. 2005).

The results from this study demonstrate that MJ elicitation strategy was quite useful to improve the yield of eleutherosides and chlorogenic acid in embryogenic cell cultures of E. senticosus. The biomass produced in the bioreactor cultures may be used as source of medicinal raw material for the extraction of eleutherosides and chlorogenic acid.

\section{ACKNOWLEDGMENTS}

One of the authors (H.N. Murthy) is thankful to Korean Federation of Science and Technology Societies (KOFST) for the award of Brain Pool Fellowship (016S-4-3-0030). We thank Dr. A.M. Reddy for critical review of this manuscript.

\section{REFERENCES}

AOYAGI, H.; KOBAYASHI, Y.; YAMADA, K.; YOKOYAMA, M.; KUSAKARI, K. and TANAKA, H. Efficient production of saikosaponins in Bupleurum falcatum root fragments combined with signal transducers. Applied Microbiology and Biotechnology, November 2001, vol. 57 , no. 4 , p. 482-488.

APERS, Sandra; NAESSENS, Tania; VAN MIERT, Sabine; PIETERS, Luc and VLIETINCK, Arnold. Quality control of roots of Eleutherococcus senticosus by HPLC. Phytochemical Analysis, January 2005, vol. 16, no. 1, p. 5560.
CHOI, Yong-Eui; YANG, Deok-Chun and YOON, EuiSoo. Rapid propagation of Eleutherococcus senticosus via direct somatic embryogenesis from explants of seedlings. Plant Cell, Tissue and Organ Culture, August 1999, vol. 58, no. 2, p. 93-97.

FARNSWORTH, N.R.; KINGHORN, A.D.; SOEJARTO, D.D. and WALLER, D.P. Siberian ginseng (Eleutherococcus senticosus): Current status as an adaptogen. In: WAGNER, H.; HIKINO, H. and FARNSWORTH, N.R. eds. Economic and Medicinal Plant Research. London, Academic Press, 1985, p. 155-215.

KETCHUM, Raymond E.B.; GIBSON, Donna M.; CROTEAU, Rodney B. and SHULER, Michael L. The kinetics of taxoid accumulation in cell suspension cultures of Taxus following elicitation with methyl jasmonate. Biotechnology and Bioengineering, January 1999, vol. 62, no. 1, p. 97-105.

KIM, Yun-Soo; HAHN, Eun-Joo; MURTHY, Hosakatte Niranjana and PAEK, Kee-Yoeup. Adventitious root growth and ginsenoside accumulation in Panax ginseng cultures as affected by methyl jasmonate. Biotechnology Letters, November 2004, vol. 26, no. 21, p. 1619-1622.

MURASHIGE, Toshio and SKOOG, Folke. A revised medium for rapid growth and bioassays with tobacco tissue cultures. Physiologia Plantarum, July, 1962, vol. 15, no. 3, p. 473-497.

SZOLOMICKI, S.; SAMOCHOWIEC, L.; WOJCIKI, J. and DROZDZIK, M. The influence of active components of Eleutherococcus senticosus on cellular defence and physical fitness in man. Phytotherapy Research, February 2000, vol. 14, no. 1, p. 30-35.

THANH, N.T.; MURTHY, H.N.; YU, K.W.; HAHN, E.J. and PAEK, K.Y. Methyl jasmonate elicitation enhanced synthesis of ginsenoside by cell suspension cultures of Panax ginseng in 5-1 balloon type bubble bioreactors. Applied Microbiology and Biotechnology, April 2005, vol. 67, no. 2, p. 197-201.

WU, J. and LIN, L. Enhancement of taxol production and release in Taxus chinensis cell cultures by ultrasound, methyl jasmonate and in situ solvent extraction. Applied Microbiology and Biotechnology, August 2003, vol. 62, no. 2-3, p. 151-155.

YAT, Patrick N.; ARNASON, John T. and AWANG, Dennis V.C. An improved extraction procedure for the rapid, quantitative high-performance liquid chromatographic estimation of the main eleutherosides (B and E) in Eleutherococcus senticosus (Eleuthero). 
Phytochemical Analysis, November-December 1998, vol. 9, no. 6, p. 291-295.

YU, Kee-Won; GAO, Wen-Yuan; SON, Sung-Ho and PAEK, Kee-Yoeup. Improvement of ginsenoside production by jasmonic acid and some other elicitors in hairy root culture of ginseng (Panax ginseng C.A. Meyer). In Vitro Cellular and Development Biology-Plant, September 2000, vol. 36, no. 5, p. 424-428.

YU, K.-W.; GAO, W.-Y.; HAHN, E.J. and PAEK, K.-Y. Jasmonic acid improves ginsenoside accumulation in adventitious root culture of Panax ginseng C.A. Meyer. Biochemical Engineering Journal, September 2002, vol. 11, no. 2-3, p. 211-215.

YUKIMUNE, Yukihito; TABATA, Homare; HIGASHI, Yosuke and HARA, Yasuhiro. Methyl jasmonate-induced overproduction of paclitaxel and baccatin III in Taxus cell suspension cultures. Nature Biotechnology, September 1996, vol. 14, no. 9, p. 1129-1132.

ZHAO, Jian; DAVIS, Lawrence C. and VERPOORTE, Robert. Elicitor signal transduction leading to production of plant secondary metabolites. Biotechnology Advances, June 2005, vol. 23, no. 4, p. 283-333. 